\title{
FORMAÇÃO AMBIENTAL E SUA RELAÇÃO COM A QUALIDADE DA ÁGUA DO RIO PIRACICABA (MG)
}

\author{
Marluce Teixeira Andrade Queiroz ${ }^{1}$ \\ Tania Gonçalves dos Santos ${ }^{2}$
}

Resumo: Este trabalho apresentou resultados de oficinas educativas para alunos do ensino fundamental de três escolas públicas de Coronel Fabriciano (MG). As metodologias aplicadas foram exposição dialogada, gincana e práticas de reuso. Para reconhecer à percepção dos educados quanto à eficácia do processo formativo foi utilizada a entrevista. Constatou-se bom nível de entendimento e sendo explicitada a preferência por atividades lúdicas que permitam efetiva concatenação com a realidade regional. Reconheceu-se que a ação demanda continuidade. É necessário estimular a reflexão, a busca de informações para compreensão das alterações existentes no mundo e desse modo capacitar o indivíduo para contribuir com a preservação ambiental.

Palavras-chave: Educação Ambiental; Resíduos; Redução; Reaproveitamento; Cidadania.

${ }^{1}$ Centro Universitário do Leste de Minas Gerais (Unileste). E-mail: marluce.queiroz@p.unileste.edu.br

2 Centro Universitário do Leste de Minas Gerais (Unileste).E-mail: taniasantos@p.unileste.edu.br 


\section{Introdução}

O cotidiano escolar engloba questões intrínsecas à relação entre educador e educado na perspectiva do desenvolvimento sustentável. Entendese que 0 acelerado desenvolvimento da sociedade tecnológica repercute favoravelmente para o conforto dos cidadãos, porém, implica em incremento da geração de resíduos em seus vários aspectos sólidos, líquidos e gasosos, desse modo, conferindo riscos para componentes bióticos e abióticos (JACOBI et al., 2009).

Verifica-se a produção de mosaico englobando bens e serviços, sendo vivenciado pela sociedade contemporânea e desse modo demandando aplicação de metodologias que contribuam para formação dos cidadãos quanto aos problemas relacionados com a produção e o descarte dos rejeitos e, necessariamente devendo conduzir para posturas proativas em relação à proteção dos recursos naturais (LUZZI, 2012). Desse modo, as demandas atuais exigem o enfretamento dos impactos negativos para a conservação das gerações presentes e influenciando a melhoria das condições para as futuras gerações, sendo a formação do cidadão essencial para a melhor eficácia do processo de intervenção do homem nas condições naturais (JACOBI, 2004).

Gambarini et al. (2006) destacam que a Educação Ambiental deve extrapolar os limites da escola tradicional e abranger os núcleos familiares. Os pesquisadores alertam quanto à necessidade da democratização do ensino. Além disso, ressaltam que devem ser idealizadas novas abordagens incluindose a experimentação com diferentes sujeitos. Tais metodologias devem ser assentadas em valores fundamentais, tal como, sustentabilidade e interdisciplinaridade (PIAGET, 1980; FERNANDEZ; FONTELA; LUZZI, 1999).

Considerando as últimas décadas pode-se afirmar que a Educação Ambiental se tornou um ponto prioritário, principalmente em função dos alertas quanto aos desastres decorrentes das interferências nos ciclos naturais e crescimento das ações de proteção que demonstram grande preocupação advinda de diferentes grupos sociais (VILLELA; EIGENHEER, 2011).

Os movimentos ecológicos passaram a ocupar posição de destaque apresentando raízes histórico-culturais e questionando fortemente as condições de vida atuais (PAXE, 2014). Nessa premissa, foram inqueridos aspectos primordiais, tal como, extinção de espécimes, desmatamento, uso de agrotóxicos, urbanização, explosão demográfica, poluição do ar e da água, contaminação de alimentos, erosão dos solos, diminuição de terras agricultáveis pela construção de barragens, ameaça nuclear, guerra bacteriológica, entre outras (ADLER et al., 2011).

O senso comum determina que a tecnologia deva estar a serviço da humanidade auxiliando nos quesitos de conforto, segurança e prolongando a expectativa de vida (JACOBI et al., 2009). Todavia, pode contribuir paralelamente para minimizar impactos adversos? O uso da tecnologia também 
pode contribuir para conter os danos pertinentes à degradação do solo, poluição das águas, contaminação do ar? Qual o papel do cidadão?

Nesse processo, surgem as indagações acerca de como vencer a ambivalência nesse percurso. Dessa maneira, inicia-se, o entendimento da dinâmica ambiental e suas repercussões sobre o bem-estar público (JACOBI et al., 2009). Vale destacar que a educação apresenta-se como ferramenta capaz de propiciar a gestão responsável de nossos recursos naturais conduzindo a sustentabilidade (PAVESI et al., 2013).

Pavesi et al. (2013) reforçam que a sustentabilidade deve definir ações e atividade humanas visando suprir as necessidades atuais, sem comprometer o futuro das próximas gerações. Ou seja, o desenvolvimento econômico e material deve existir em conformidade com o uso dos recursos naturais de forma inteligente. Trata-se de requisitos indispensáveis para garantir o futuro.

Assim, a ideia do presente estudo foi avaliar a formação ambiental com uso de técnicas de reaproveitamento de resíduos não contaminados em atividades acadêmicas que permitissem o entendimento dos conceitos dos ciclos de vida, da sustentabilidade, etc. Neste contexto, este trabalho objetivou apresentar e analisar os resultados alcançados em atividades realizadas no desenvolvimento do I Encontro Socioambiental da Região Metropolitana do Vale do Aço onde foram reunidos professores e discentes de três escolas públicas municipais, sendo localizadas na porção leste do Estado de Minas Gerais, Brasil. As atividades foram coordenadas por docentes do Centro Universitário do Leste de Minas Gerais (Unileste) com adesão de graduandos que integravam os projetos institucionais de extensão e ocorreram na sede do Sindicato dos Trabalhadores em Transporte Rodoviário (SINTTROCEL).

Segundo Oliveira et al. (2008) as metodologias aplicadas para o desenvolvimento da Educação Ambiental devem ser encaradas como um laboratório e aplicados para aperfeiçoar as políticas públicas educacionais. Lima et al. (2003) enfatizam que as práticas vivenciadas devem ser disponibilizadas contribuindo para produção de conhecimentos e formação da cidadania. Atentase que a divulgação dos resultados desse estudo oportuniza o delineamento de outras ações educacionais similares. Buscou-se, sobretudo, contribuir para a construção de um saber mais sistêmico e contextualizado potencializando entre os atores sociais a adoção de uma postura proativa em relação aos problemas ambientais.

\section{Materiais e Métodos}

\section{Formação das equipes e tarefas}

Os integrantes do projeto de extensão Educação Ambiental do Unileste ficaram responsáveis pela coordenação pedagógica, planejamento e orientação das atividades didáticas pertinentes ao I Encontro Socioambiental da Região Metropolitana do Vale do Aço e definindo pela execução em duas etapas. Em 
um primeiro momento, os professores das três unidades escolares ficaram encarregados quanto à transmissão das informações para os alunos e motiválos para a participação. Um total de 180 (cento e oitenta) discentes atendeu ao convite.

Os educados foram divididos em 6 (seis) equipes de 30 (alunos), sendo preferencialmente da mesma escola, tendo um professor para atuar como 0 coordenador da equipe.

A programação geral do evento incluiu a realização de exposições dialogadas e gincana ambiental, sendo a participação dos discentes e resultados alcançados avaliados com pontuação específica atribuída para cada equipe. Os conteúdos foram discutidos tratando problemas ambientais regionais considerando o conhecimento prévio dos educados, sendo os expositores mediadores para que os ouvintes alcançassem condições para questionar, interpretar e discutir os temas abordados (REPETTO et. al., 2013).

A proposta enfatizava a relação entre as condições antrópicas e degradação dos rios e nascentes; explicitando a relevância do exercício da cidadania para o enfrentamento das distorções. Nessas atividades foi aplicada a técnica do estudo fotográfico para a discussão de questões tais como, deposição inadequada do lixo domiciliar, queimadas, economia de energia e água, expondo a relação entre qualidade ambiental, saúde e longevidade. As exposições dialogadas alcançaram um tempo médio de 30 (trinta) minutos, seguido de intervalo de 10 (dez) minutos para discussão. Nesse quesito, optou-se pelo debate orientado, sendo algumas questões formuladas por universitários integrantes da equipe executora. No entanto, o tempo poderia ser estendido em 5 (cinco) minutos para atendimento de possíveis questionamentos aleatórios. A metodologia buscou atrair a atenção dos participantes propiciando uma maior interação com os expositores e motivando-os para explanarem suas dúvidas e conclusões sobre a temática. Cavasini et al. (2016) pontuam que o uso desse recurso contribui para eliminar a falta de feedbacks, possibilitando retenção das informações recebidas em exposição oral.

A segunda etapa consistiu basicamente na gincana ambiental, que incorporou jogos de competição e lúdicos. A inclusão dos jogos de competição foi motivada na perspectiva do desenvolvimento de habilidades específicas, tais como, o raciocínio lógico e a perspicácia (BEZERRA et al., 2003). As tarefas exigiram a confecção de material educativo, incluindo a produção de cartazes com o objetivo de incentivar a população para a prática da proteção ambiental. Além disso, promoveu o envolvimento da comunidade através da arrecadação de garrafas plásticas, vidro, alumínio, dentre outros, que foram doados para a associação de catadores de lixo da região de estudo. Outro ângulo de ação representado pelos componentes lúdicos implicou no prazer de representar, cantar, e exigiu diversas habilidades cognitivas tais como, a criatividade, 0 dinamismo e a capacidade de articulação (QUEIROZ; MELO, 2004). 
As tarefas (Quadro 1) consistiram na elaboração e apresentação do grito de guerra, peça teatral, poesia, dança e música relacionadas com o tema do encontro e tiveram como premissa a sensibilização dos educados quanto à urgência de ações mitigadoras em relação à poluição da água e do solo. De modo geral, a dinâmica buscou contribuir com a construção de significados positivos relacionados com a proteção do meio ambiente com base em aspectos econômicos, sociais e éticos.

Quadro 1: Pontuação e atividades do I Encontro Socioambiental da Região Metropolitana do Vale do Aço.

\begin{tabular}{|c|c|c|}
\hline Tarefa & Indicador & Pontuação \\
\hline $\begin{array}{c}\text { Participação na } \\
\text { exposição dialogada }\end{array}$ & $\begin{array}{c}\text { Número de Presentes da Escola } \\
\text { (alunos, professores, familiares). }\end{array}$ & $\begin{array}{c}\text { 10 Pontos (100\% dos alunos inscritos) } \\
\text { 05 Pontos (Qualquer ausência inferior } \\
\text { ao total de alunos inscritos) } \\
\text { 00 Ponto (Qualquer ausência sem } \\
\text { justificativa médica). }\end{array}$ \\
\hline Cartaz & $\begin{array}{c}\text { Frase inédita com redação } \\
\text { ortográfica correta estimulando a } \\
\text { comunidade para ações de proteção } \\
\text { ambiental dos recursos hídricos }\end{array}$ & $\begin{array}{c}\text { Primeiro Colocado: 10 Pontos } \\
\text { Segundo Colocado: 05 Pontos } \\
\text { Terceiro Colocado: 2,5 Pontos }\end{array}$ \\
\hline Grito de Guerra & $\begin{array}{c}\text { Bordão elaborado pela equipe para } \\
\text { estimular a proteção ambiental dos } \\
\text { recursos hídricose animar os } \\
\text { competidores }\end{array}$ & Tarefa cumprida: 10 pontos \\
\hline $\begin{array}{c}\text { Apresentação de } \\
\text { Artefato Reciclado ou } \\
\text { Reaproveitado }\end{array}$ & $\begin{array}{c}\text { Apresentação do objeto para } \\
\text { avaliação da comissão julgadora } \\
\text { para definição da classificação final }\end{array}$ & $\begin{array}{c}\text { Primeiro Colocado: 10 Pontos } \\
\text { Segundo Colocado: 05 Pontos } \\
\text { Terceiro Colocado: 2,5 Pontos }\end{array}$ \\
\hline
\end{tabular}

\section{Premiação}

A premiação é uma técnica comumente empregada para favorecer o desenvolvimento dos fatores motivacionais internos, ou seja, dos sentimentos intrínsecos individuais fomentados através do reconhecimento público decorrentes dos seus atos (OLIVEIRA, 2017).

Nessa perspectiva, a premiação para as equipes vencedoras consistiu em entrega de troféu, para os três primeiros colocados, sendo que todos os integrantes da equipe campeã (primeiro lugar) receberam também medalha. Como prêmio também foi concedido uma visita orientada em uma reserva ecológica para as três equipes vencedoras, incluindo-se alimentação e transporte.

Os graduandos integrantes do projeto de extensão do Unileste juntamente com representantes do SINTTROCEL atuaram como avaliadores das equipes com relação ao cumprimento das tarefas da gincana. 


\section{Coleta de dados}

A fim de realizar uma interpretação crítica com relação às atividades que foram desenvolvidas durante 0 । Encontro Socioambiental da Região Metropolitana do Vale do Aço, foi aplicado um questionário adaptado de Mergulhão e Trivelato (2005), com perguntas objetivas sendo solicitado o apontamento de uma única alternativa considerada pelo entrevistado como a mais relevante, e entrevistas semiestruturadas, que foram transcritas. Todas as atividades deveriam ser classificadas pelos discentes como ruim, regular, boa e muito boa. Foram classificadas como atividades satisfatórias aquelas que atingiram um percentual de pelo menos $80 \%$ utilizando-se o somatório dos critérios de classificação, atividade muito boa e atividade boa.

Em relação às palestras, mensurou-se, através das entrevistas, o grau de satisfação dos participantes em relação ao tempo, linguagem e dinâmica do trabalho. Buscou-se identificar a compreensão alcançada pelos discentes e pontos a serem melhorados.

Com relação aos jogos da gincana ambiental procurou-se identificar nível de interesse, percepção dos discentes em relação ao conteúdo das tarefas e satisfação em relação aos resultados alcançados. Além disso, se avaliou a disposição dos participantes para proatividade direcionada à proteção do meio ambiente.

\section{Resultados e Discussão}

\section{Aderência ao Processo de Avaliação da Oficina Educativa}

Sabe-se que o crescimento educacional se relaciona com a avaliação continuada quanto ao seu padrão de desempenho de forma globalizada e sistêmica. Essa mensuração deve propiciar a identificação das metodologias mais apropriadas, ou seja, produzir avanços. Nesse sentido, os questionários adaptados de Mergulhão e Trivelato (2005) foram respondidos por docentes e discentes participantes do I Encontro Socioambiental da Região Metropolitana do Vale do Aço.

Em relação ao total de 180 (cento e oitenta) participantes, apenas 77 (setenta e sete) aderiram ao processo de avaliação, correspondendo a $42,8 \%$ dos discentes. Acredita-se que a pressão do tempo foi um fator que contribuiu para que o nível de adesão ficasse abaixo de $50 \%$. As atividades extrapolaram o tempo previsto e muitos dos discentes já tinham outros compromissos agendados. Além disso, faltou explicitar para a comunidade atendida a sequência do trabalho através de um cronograma de ações claramente apresentado e discutido com os educados. Tais condições sugerem relação com a falta de motivação para responder ao questionário. Em relação aos docentes o fato não impediu a aderência dos 20 (vinte) docentes envolvidos diretamente no evento. Vale ressaltar, que os diretores dos educandários já haviam se organizado indicando professores que não tinham aulas previstas para o turno 
noturno, sendo as horas apuradas como aperfeiçoamento em atividades extraclasse.

\section{Motivação dos Discentes e Docentes}

A interação de qualquer ser humano em uma atividade se relaciona com a motivação. Diversos pesquisadores pontuam que fatores intrínsecos e extrínsecos se inserem nesse quesito. Nesse sentido, a recompensa ativa os centros neurológicos que geram bem-estar mobilizando a atenção do indivíduo reforçando 0 comportamento na direção do dispositivo detonador (BORUCHOVITCH, 2009, BZUNECK, 2001). Nestes tempos em que a informação assume um papel cada vez mais relevante, ciberespaço, multimídia, internet, a educação para a cidadania representa a possibilidade de motivar e sensibilizar as pessoas para transformar as diversas formas de participação na defesa da qualidade de vida (JACOBI, 2003).

Tamaio (2000) afirma que, o educador tem a função de mediador na construção de referenciais ambientais e deve saber usá-los como instrumentos para o desenvolvimento de uma prática social centrada no conceito da natureza. Röhr (2016) reforça a importância do desenvolvimento das capacidades cognoscitivas, a formação de atitudes e convicções frente à realidade social do aluno.

Os resultados obtidos indicaram que os professores das escolas públicas souberam explicitar de forma adequada à proposta do evento, obtendo um nível de adesão bastante satisfatório. Nessa premissa, os discentes foram questionados quanto à motivação para participar do evento e as respostas obtidas surpreenderam positivamente já que $32,5 \%$ vieram com o objetivo de aprender mais e $54,5 \%$ pela temática. Vale destacar que a premiação totalizou $0,0 \%$ enquanto diversão e competição alcançaram respectivamente $2,6 \%$ cada uma e determinação da escola 5,2\%.

Em relação aos docentes a mesma pergunta obteve resultados correspondentes a $40 \%$ aprofundar o conhecimento quanto à aplicação desse mecanismo auxiliar de aprendizagem e $60 \%$ pontuaram quanto à premência do estreitamento da relação com os discentes e família visando à formação em cidadania. Os resultados indicaram a relevância da interação com a comunidade sob a ótica do docente. Com base na entrevista foi possível identificar que os docentes demandavam por maiores investimentos na educação ao nível da realidade nacional. Destaca-se que a precariedade dos recursos para aulas práticas foi apontada como a grande dificuldade no ensino das ciências.

Além disso, historicamente os professores vêm paulatinamente sendo submetidos a gestões públicas que conduzem a redução do empenho em função do desinvestimento na educação constituindo-se desse modo em um fator contributivo ponderável e exigindo expediente governamental (PEDRO; PEIXOTO, 2006). Além disso, nos últimos tempos, no Brasil e no exterior, se 
tornou rotineira na mídia a veiculação de matérias referentes a casos de agressões sofridas por professores e alunos dentro de sala explicitando a necessidade da concepção e aplicação de abordagens capazes de resgatar o respeito e admiração mútuos (MALDONADO; WILLIAMS, 2005).

\section{Exposição Dialogada}

As exposições dialogadas desenvolvidas no I Encontro Socioambiental da Região Metropolitana do Vale do Aço a construção de conhecimentos com foco na realidade regional de forma atrativa. A estratégia buscou contribuir para compreensão dos fenômenos ambientais, elucidação seus respectivos arcabouços teóricos subsidiando as discussões aprofundadas, a saber: a natureza e as formas de interação com o homem em sua realidade imediata e desse modo concretizando informações significativas para fortalecimento do caráter e cidadania (MARIN et al., 2003).

A primeira abordagem foi direcionada para a formação de ideias e de conceitos firmados com perguntas sobre a qualidade das águas superficiais dos principais rios que percorrem a RMVA, tal como o Rio Piracicaba e Ribeirão Caladinho, sendo apresentados resultados de pesquisas científicas que demonstravam o alto nível de degradação, associado à deposição de esgoto doméstico sem tratamento e lixo urbano domiciliar, dentre outros fatores (QUEIROZ et al., 2015).

Em relação a esta atividade verificou-se que $91 \%$ do total de entrevistados classificaram-na como muito boa (Figura 1). Segundo os participantes da pesquisa a linguagem coloquial e adoção de uma postura favorável ao debate, foram os pontos fortes da atividade.

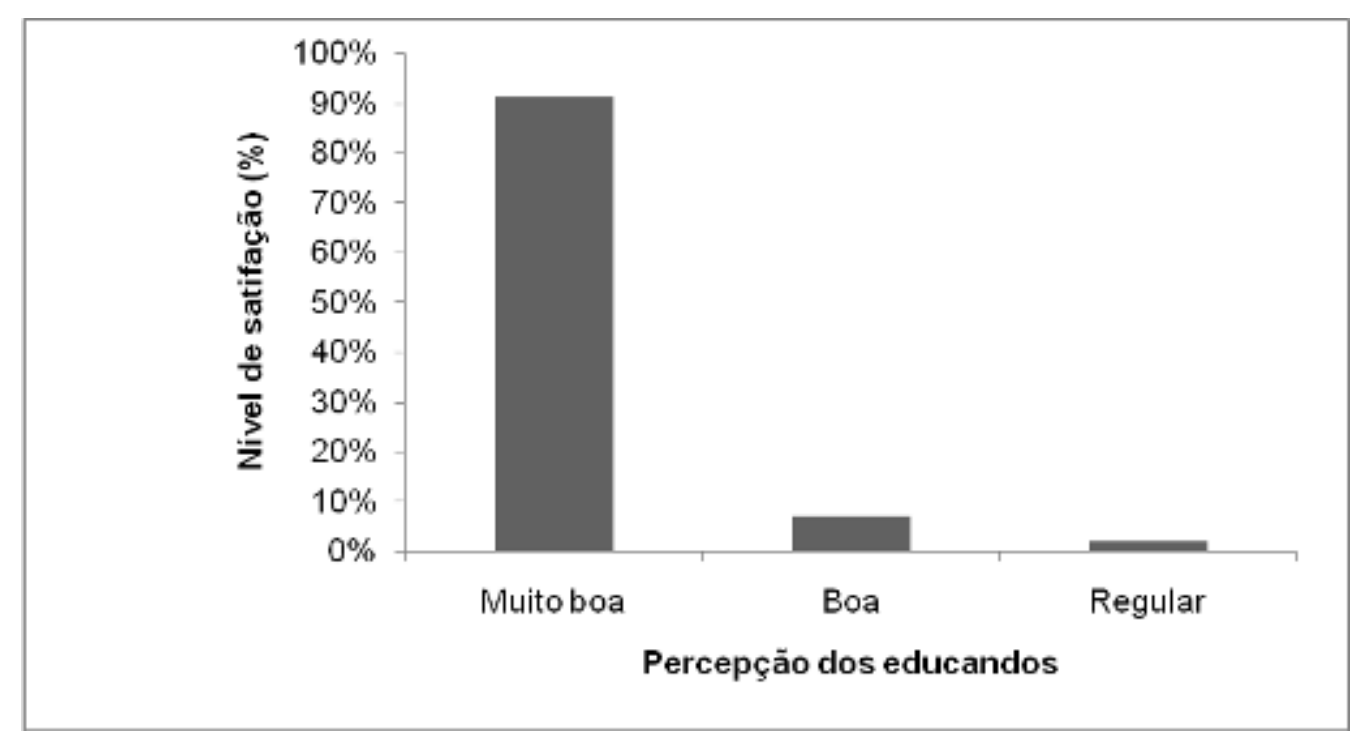

Figura 1: Percepção dos Discentes - Exposição Dialogada sobre Qualidade da Água. 
Os resultados alcançados sugeriram relação com a técnica aplicada pelo expositor. Exemplificando, o estudo fotográfico sobre o Ribeirão Caladinho, surpreendeu os participantes, em função da grande quantidade de lixo urbano sendo depositado diariamente naquele corpo d'água. Também foi identificado lançamento de esgoto doméstico e entulho no corpo d'água em quantidades elevadas e absurdamente distanciados da proposta de preservação ambiental, desse modo, incomodando a comunidade ao se deparar com o aquele estado caótico. Tratou-se da interpretação reflexiva da realidade que se transforma em conhecimento e oportuniza a identificação da relação do homem com o seu habitat repercutindo favoravelmente no dinamismo social (VALLE; BOGA, 2012).No entanto, as dificuldades para visualização dos conteúdos foi o principal fator indicado pelos entrevistados que classificaram a atividade como boa $(7 \%)$ e regular (2\%) (Figura 1). Explicitou-se aí, a necessidade da realização do trabalho educativo com grupos menores, favorecendo o debate e a observação dos detalhes pertinentes ao estudo fotográfico.

A segunda atividade expositiva dialogada foi direcionada para estimular - estresse positivo da dúvida em relação à implantação da Estação de Tratamento de Esgoto (ETE) no município de Coronel Fabriciano, Minas Gerais, Brasil. Coimbra e Spigolon (2010) destacam que essa técnica exige que o expositor apresente competência para cativar a atenção aplicando a arte da pergunta atingindo o território da emoção no anfiteatro das mentes. Os pesquisadores reforçam que a dúvida provoca a inteligência, desse modo, infere-se que possíveis avanços sociais sejam alcançados através da preocupação com o saneamento, descarte irresponsável de resíduos e escassez de recursos naturais.

Esta atividade foi classificada como muito boa por $77,9 \%$ dos entrevistados (Figura 2). Um fator negativo apontado pelos entrevistados foi à extrapolação do tempo de quarenta minutos. Silva e Cunha (2018) alertam que um grande desafio para a educação é conjugar o tempo para aplicação da atividade com a aprendizagem. $O$ descompasso propicia ansiedades e frustrações (ARAÚJO; CUNHA, 2017). Nesse contexto, alerta-se quanto à relevância de diminuir essas condições de não conformidades.

Outro aspecto, a linguagem muito técnica foi apontada como fator de dificuldade, por aqueles que classificaram a atividade como boa $(18,2 \%)$ e regular (3,9\%), explicitando a necessidade de melhorias neste quesito. 


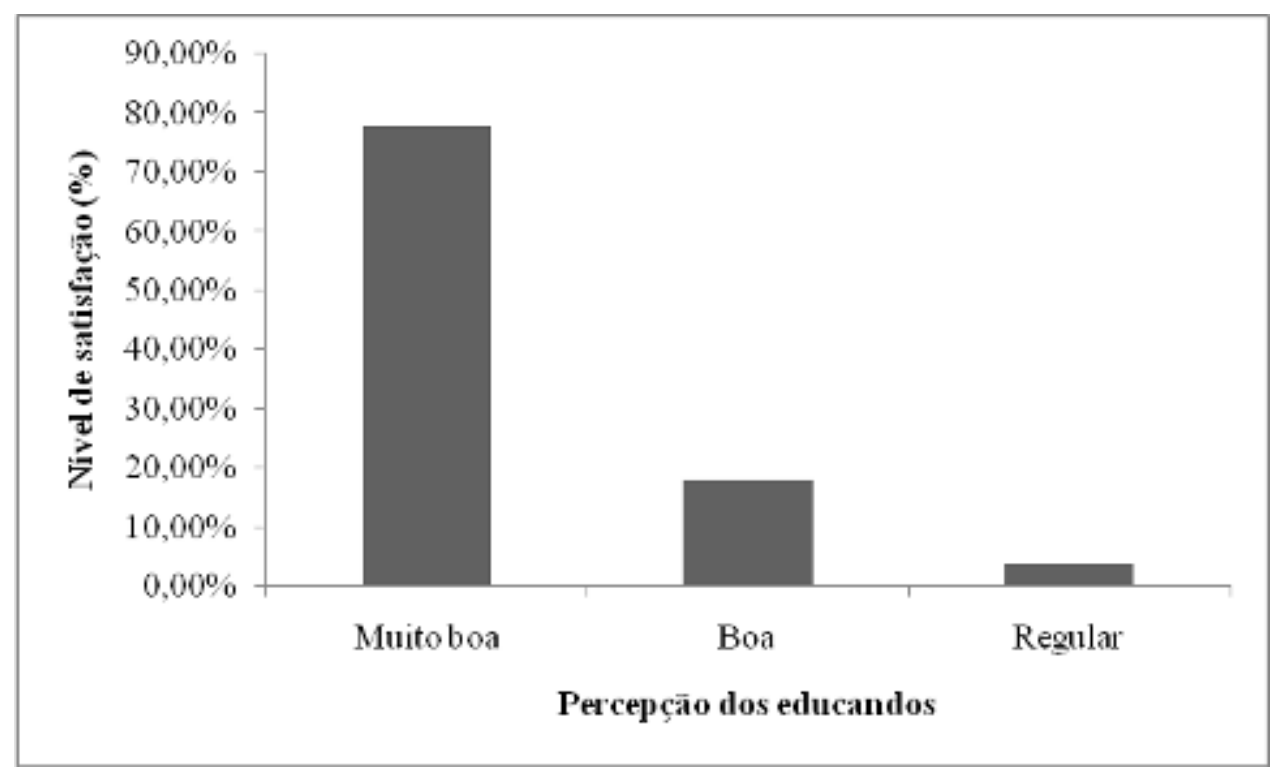

Figura 2 :Percepção dos Discentes - Exposição Dialogada sobre ETE.

Os resultados evidenciaram que para se alcançar a compreensão do público jovem à linguagem deve ser colocada em patamares mais acessíveis ou, pelo menos, menos rebuscada e facilitando a difusão do pensamento ecologicamente correto. Uma proposta seria trabalhar na fase preparatória os conceitos de forma fragmentada e evoluindo progressivamente em estágios de forma a se atingir o nível de compreensão almejado (VALE e BOGA, 2012).

Uma informação de fácil entendimento melhora o conhecimento e conseqüentemente a condição para o enfretamento em relação aos problemas ambientais, ajuda a desenvolver atitudes, facilita a autonomia, promove adesão, tornando-os capazes de entender como as ações do homem influenciam na preservação do meio ambiente (LUZZI, 2012). Vale destacar que a exposição dialogada foi contextualizada contribuindo de forma inequívoca para o protagonismo daquela comunidade com busca de ações coletivas e afirmativas, com participação na vida pública e nas tomadas de decisões (ARAÚJO E CUNHA, 2017). Os resultados explicitaram a necessidade de aprofundamento na fase preparatória discutindo em sala de aula tecnicamente as disfunções ambientais e o papel do cidadão nesse contexto.

\section{Gincana Ambiental}

$\mathrm{Na}$ sociedade atual a relação entre jogo e educação tem sido muito discutida. Brincar é compreendido como um espaço privilegiado para as crianças, jovens e até mesmo adultos, recriarem a realidade vivida e compreendê-la (CHACON et al., 2004). O jogo é, portanto, visto como um espaço de experimentação de regras, de troca de experiências, de afinamento de habilidades, de interação social, de comunicação, etc. Aplicar jogos de 
Educação Ambiental neste sentido é incluir proposta com repercussões positivas nas relações de ensino/aprendizagem (LEAL, 2011).

$\mathrm{Na}$ atividade de gincana ambiental, a primeira tarefa, constitui-se na elaboração do grito de guerra por cada uma das equipes. Esta tarefa é comum em gincanas, ajudam a descontrair. No entanto, a sua principal função é unir ainda mais as pessoas em torno do ideal comum (NEVES, 2003). Neste trabalho, o grito de guerra deveria incorporar o tema e motivar as pessoas para ações de proteção ambiental. Todas as equipes realizaram a tarefa e receberam a mesma pontuação, já que o critério era apenas tarefa cumprida ou não cumprida.

Em relação à tarefa constatou-se que apenas 75,3\% classificaram-na como muito boa (Figura 3). Os entrevistados que consideraram a tarefa boa $(20,8 \%)$, regular $(2,6 \%)$ e ruim $(1,3 \%)$ afirmaram que existiam equipes que não haviam trabalhado de forma satisfatória e mesmo assim receberam a mesma pontuação. No entanto, atingiu $96,1 \%$ de aprovação utilizando-se o somatório da classificação tarefa muito boa e tarefa boa. Vale destacar que a tarefa contribuiu para fortalecer o elo entre as equipes e alertar a coletividade sobre a importância da proteção dos recursos naturais. Uma gincana requer trabalho de equipe, de grupo. Por isso, é fundamental que todos se integrem e participem ativamente (ANDRADE, 2005). Favorecendo o trabalho em equipe as pessoas são estimuladas para agirem em prol de um determinado fim, no caso, manutenção da vida no planeta. Entende-se que é conveniente a existência de algumas provas que sejam pontuadas apenas em relação ao cumprimento da tarefa. Se houver um distanciamento muito grande entre as pontuações logo na primeira atividade, pode ocorrer o desestímulo das equipes. Neste caso, o trabalho educacional poderá ser prejudicado (LEAL, 2011).

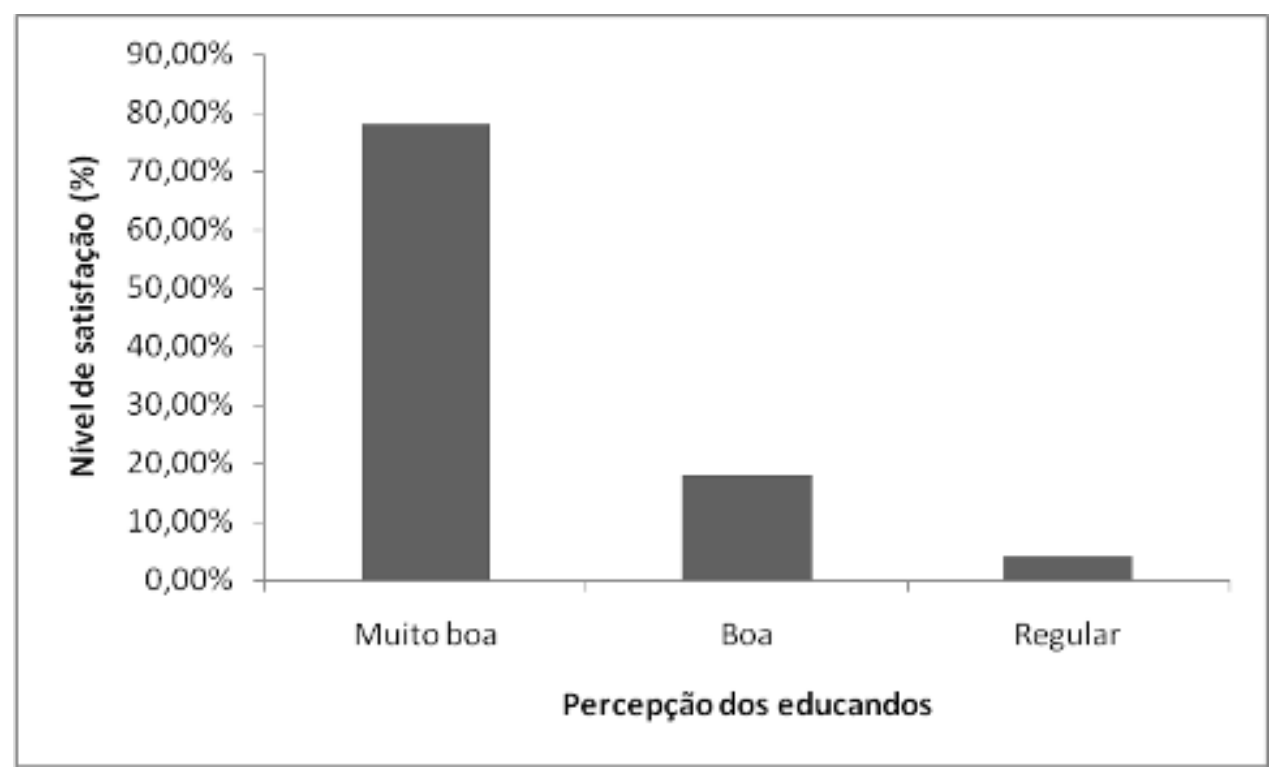

Figura 3: Percepção dos Discentes - Tarefa Grito de Guerra, durante a Gincana Ambiental. 
A segunda tarefa incorporou o componente lúdico e a competição. As equipes deviam apresentar desenhos com o tema do evento, de tal forma a motivar a comunidade para adoção de uma postura pró-ativa em relação ao meio ambiente. A equipe que produzisse o melhor desenho obteria a maior pontuação. Esta atividade recebeu ampla aprovação, atingindo um grau de satisfação muito elevado. Verificou-se que $85,7 \%$ dos entrevistados classificaram-na como muito boa, enquanto $14,3 \%$ a identificaram como boa. Os resultados denotaram que a associação entre o componente lúdico e a competição, favoreceu a adesão dos participantes do evento. Entende-se que este seja um fator motivacional que deva ser explorado amplamente nas atividades de Educação Ambiental. Piaget (1980) e Piaget e Inhelder (1984) destacam que o desenhar representa, em parte, a mente consciente, mas também é uma forma interessante de fazer uma conexão com o inconsciente. Portanto essa manifestação repleta de simbolismo e mensagens contribui para o desenvolvimento da consciência social capaz de transferir suas potencialidades para o campo real.

A terceira tarefa incorporou também o componente lúdico e a competição. As equipes deveriam produzir objetos a partir de atividades de reuso ou reciclagem (Figura 4). O critério de julgamento se relacionou com a beleza e aplicabilidade.

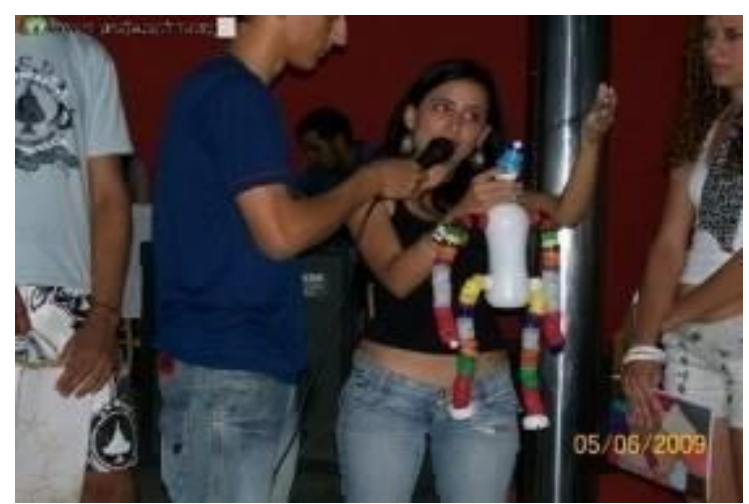

Figura 4: Brinquedo com material reaproveitado, durante a Gincana Ambiental.

Esta atividade foi a que atingiu o menor nível de satisfação, apenas $62,3 \%$ dos entrevistados, avaliaram a atividade como muito boa. Com base nos depoimentos orais e escritos foi possível verificar que os aspectos relativos à insatisfação estavam associados às dificuldades para atender aos requisitos de beleza e aplicabilidade com base na reutilização de materiais que seriam a priori descartados. Dias (2000) afirma que o ensino da Educação Ambiental é importante para a conscientização e formação das pessoas, de tal forma que a prática da reciclagem e reuso faça parte do cotidiano. Ramos (2009) pontua que 
um agravante são as exigências de consumo impostas pela sociedade moderna. Neste contexto, entendem-se as dúvidas dos discentes quanto ao atendimento dos requisitos de avaliação propostos.

Cabem aí, ações dos educadores que ajudem a demonstrar que a beleza do reuso ou reciclagem se relaciona com a efetiva aplicação do rejeito para outra finalidade e desse modo contribui efetivamente para a preservação dos recursos naturais (RAMOS, 2010). Kobayashi et al. (2015) ressaltam a importância de perceber e incentivar a capacidade criadora das pessoas, pois esta se constitui numa das formas de relacionamento e recriação do mundo, na perspectiva da lógica e promovendo a situação de transição entre proteção ambiental e ações expressivas. No entanto, utilizando-se os critérios atividade muito boa e boa, o nível de aprovação atingiu $88,3 \%$ sendo satisfatório.

A quarta tarefa tratava da apresentação de uma peça teatral que deveria explicitar a temática relativa à necessidade de proteção das águas superficiais, também incorporando o componente lúdico e a competição entre as equipes. Rojo (2015) alerta que o teatro deve servir para pensar e refletir criticamente, devendo ser adotado como modelo didático e incorporando experiências científicas durante a trama viabilizando sempre que possível à participação do público como componente essencial no desempenho. De acordo com Vianna e Strazzacappa (2001), o valor educativo da arte se inicia no próprio exercício da imaginação, que proporciona um olhar diferenciado sobre a realidade, investigando-a, criando diferentes possibilidades de compreendê-la e de, principalmente, atuar sobre ela. A arte estimula o senso perceptivo, o aguçar dos sentidos, aumentando a capacidade de interpretação e julgamento do indivíduo. Também, propicia o exercício da sensibilidade, trabalhando com o universo de emoções do ser humano e com a livre-expressão da subjetividade, criando uma diferente forma de comunicação entre as pessoas. Ainda, a arte-educação, ao trabalhar com o estímulo da criatividade, se faz como uma forma de desenvolver o autoconhecimento e o exercício da busca de novas soluções no dia-a-dia (CASTRO-POZO, 2009).

Apenas $70,1 \%$ dos entrevistados consideram a tarefa muito boa, enquanto $11,7 \%$ classificou a atividade como boa, enquanto $14,3 \%$ como regular e 3,9\% como ruim. Novamente, a meta de $80 \%$ foi atingida em observância aos quesitos muito boa e boa. Os entrevistados que classificaram a atividade como regular ou ruim, pontuaram que a complexidade em algumas dramatizações apresentadas não atendeu as expectativas, denotando que a insatisfação não estava associada ao desenvolvimento da tarefa em si, mas com relação à qualidade do produto final. Estes resultados sugeriram que o fator competição estava associado à avaliação negativa quanto aos trabalhos apresentados pelos discentes. Vale destacar, que a comissão julgadora classificou as apresentações teatrais como de ótimo nível.

A última tarefa da gincana consistiu em uma atividade de apoio a um estabelecimento beneficente de recuperação de mulheres portadoras de 
dependência química, situado no bairro Córrego Alto, em Coronel Fabriciano. Cada equipe deveria arrecadar o maior número de litros de leite longa vida para ser entregue à instituição através da equipe campeã da gincana e demais interessados em participar.

Verificou-se que o total correspondente a $58,4 \%$ e $31,2 \%$ dos entrevistados, classificou a atividade como muito boa e boa respectivamente tendo em vista a possibilidade de ajudarem pessoas a alcançarem uma alimentação mais rica em nutrientes, totalizando $89,6 \%$ de aprovação. A classificação regular foi aplicada por $10,4 \%$ dos entrevistados que alegaram dificuldades para arrecadação dos litros de leite.

Outro fator positivo associado a estava atividade foi à repercussão alcançada junto à comunidade local, favorecendo a participação de pessoas das mais diversas faixas etárias com a inclusão de idosos. Foram também produzidos panfletos contendo informações sobre o valor nutricional do leite. Diversos estudos pontuam quanto à importância do leite como fonte de cálcio para a boa saúde dos dentes e ossos mesmo na fase adulta. Especificamente no climatério a redução desse nutriente se constitui em problema grave redundando na fragilização óssea que pode evoluir desencadeando fraturas limitantes (MEDEIROS et al., 2012). Certamente um alerta importante se relaciona com a ingestão excessiva que pode redundar em efeitos deletérios sendo recomendado pela Organização Mundial de Saúde que a relação de cálcio/proteína seja de 20/1 mg.g ${ }^{-1}$ (GOMES; FERNANDES, 2011). Dessa forma, a tarefa também se inseriu na produção de uma Educação Ambiental crítica, impregnada pela utopia de mudar radicalmente as relações (homem-homem e homem-ambiente) que conhecemos hoje e certamente contribuir para a longevidade humana (ANDRADE et al., 2000).

\section{Conclusões}

A proposta do I Encontro Socioambiental da Região Metropolitana do Vale do Aço foi motivar participantes para uma gestão responsável em relação à proteção das águas superficiais, apresentando algumas estratégias de atuação para a redução de resíduos, reaproveitamento e reciclagem. Sendo assim, se buscou enfatizar a educação enquanto processo permanente e coletivo pelo qual agimos e refletimos, transformando a realidade e avançando através da cidadania. A atividade se relacionou com as profundas dicotomias que afetam o homem contemporâneo. Atualmente, raramente o indivíduo apresenta plena consciência da sua participação como um elemento da natureza, posicionandose, muitas vezes, como um ser à parte, um observador, explorador e dominador da mesma e buscando fundamentar suas ações equivocadas. Verifica-se aí a premência de uma mudança nessa visão de mundo.

A alta receptividade dos discentes e docentes participantes do evento e o nível de conscientização atingido explicitado nos resultados evidenciou que o ensino tradicional não é a melhor opção para a formação de uma cultura de 
proteção do meio ambiente. Esses alunos levarão o que aprenderam para a vida, e decidirão, por meio de suas ações, o futuro do ambiente que os cerca.

Destaca-se que o modelo utilizado no encontro extrapolou os limites da mera transmissão de conhecimentos favorecendo a formação da cidadania responsável nessa sociedade científica e tecnológica que vivenciamos e aguçou a criatividade dos participantes contribuindo para direcioná-los na valoração do ser humano e seu habitat.

Especificamente em relação ao uso gincana como instrumento didáticopedagógico foi possível verificar a sua importância permitindo o desenvolvimento de atividades direcionadas para reflexão de questões ambientais cruciais em um formato dinâmico e interativo oportunizando de forma eficaz a conscientização dos alunos em relação aos problemas atuais com inclusão de ações que podem ser incorporadas à rotina escolar.

Os resultados alcançados explicitaram também a primordialidade da constância pertinente a integração entre instituição de pesquisa, escolas de ensino fundamental e médio, empresa, organizações não governamentais e governo, buscando relacionar a educação em ciência com os aspectos econômicos e éticos. Constatou-se que há necessidade de continuidade e aprofundamento das discussões. Ações pontuais perdem em eficácia já que não contribuem satisfatoriamente para a formação de cidadãos críticos.

\section{Agradecimentos}

Ao Conselho Nacional de Desenvolvimento Científico e Tecnológico (CNPq), pelo apoio à pesquisa; ao Centro Universitário do Leste de Minas Gerais (Unileste), por tornar possíveis as atividades de extensão.

\section{Referências}

ADLER, R. R.; FERREIRA, J, A.; EIGENHEER, E. M.. Implantação dos aterros propostos no Plano Diretor de Gestão Integrada de Resíduos Sólidos da Região Metropolitana do Rio de Janeiro através de empresas privadas. Mundo \& Vida (UFF), v. 12, p. 11-13, 2011.

ANDRADE, R. O. B.; TACHIZAWA, T.; CARVALHO, A. B.. Gestão Ambiental: Enfoque Estratégico Aplicado ao Desenvolvimento Sustentável. São Paulo: MAKRON books, 2000: 179 a 198.

ANDRADE, C. M.. Uma Escola para Todas as Idades. Anais do VII Seminário Internacional de Educação, 2005, ljuí. VII Seminário Internacional de Educação, 2005.

ARAÚJO, S.P. ; CUNHA, M. C. . Avaliação em larga escala, formação de professores e letramento: entre concepções e práticas no ensino fundamental. Domínios de Linguagem, v. 11, p. 10-20, 2017. 
BEZERRA, E.J.; CHACON FILHO, A.O.; LUCENA, S.M.P.O.; CAVALCANTI, K.B. Lazer Pesquisa e Extensão: articulação necessária a projetos de animação sócio-cultural em parques. Anais do ENAREL- XV Encontro Nacional de Recreação e Lazer, 2003, Santo André - SP. Anais do XV ENAREL - Lazer e Trabalho: Novos significados na sociedade contemporânea, 2003.

BORUCHOVITCH, E. A motivação do aluno (4. ${ }^{a}$ ed.). Rio de Janeiro: Editora Vozes. 2009.

BRASIL. Ministério da Educação. Coordenação Geral de Educação Ambiental. Relata os programas, projetos e ações desenvolvidos, 2007. Disponível :<http://www.mec.gov.br/secad>, Acesso: 13/08/2013.

BRASIL ESCOLA. Estratégias de Ensino - Educador, 2010. Disponível:<http://www.brasilescola.com/> Acesso: 14/08/2015).

BZUNECK, J.A., 2001. O esforço nas aprendizagens escolares: mais do que um problema motivacional do aluno. Revista Educação e Ensino - USF, 6, 7-18.

CASTRO-POZO, T. Saberes, sonhos e muros. Arte e Cultura da América Latina, v. XXI, p. 79-88, 2009.

CAVASINI, R.; BREYER, R.F.; PETERSEN, R.D.S. Uma Abordagem de Gestão de Riscos para Atividades de Educação Ambiental ao Ar Livre. Revista Brasileira de Educação Ambiental, vol. 11, n. 4, 2016.

COIMBRA, C. L.; SPIGOLON, N.. Inspirações e práxis freireana: contribuições de Elza Freire para o diálogo e a convivência. Caderno de Textos do GEPEJA (UNICAMP)), v. 01, p. 78-86, 2010.

DIAS, G. F. Educação Ambiental. 6.ed. São Paulo: Gaya, 2000.

GAMBARINI, C.; BASTOS, F. A utilização do texto escrito por professores e alunos nas aulas de Ciências. In: NARDI, R.; ALMEIDA, M. J. P. M. (Orgs.). Analogias, leituras e modelos no ensino da ciência: a sala de aula em estudo. São Paulo: Escrituras, 2006.

GOMES, K. V.; FERNANDES, M. I. A. A dependência química em mulheres: figurações de um sintoma partilhado. In: Anais do XIX Congresso Latinoamericano FLAPAG, XVII Jornada AAPPG e XXVII Jornada Nacional FAPCV, 2011, Buenos Aires - Argentina. Anais do Congresso el Psicoanálisis Vincular de Latinoamérica. Lo singular - lo múltiple. Buenos Aires - Argentina, 2011.

FERNANDEZ, L.; FONTELA, M.; LUZZI, D. A.. Apontes para o tratamento jurídico do ambiente. 1. ed. Buenos Aires: Senado da Nação Argentina, Comissão de Ecologia, 1999. v. 1. 300p

JACOBI, P. R. Educação e Meio Ambiente- Transformando as Práticas. Revista Brasileira de Educação Ambiental, Brasilia, v. 0, p. 28-35, 2004. 
JACOBI, P. R.; TRISTÃO, M.; FRANCO, I. . A Função Social da Educação Ambiental nas Práticas Colaborativas:Participação e Engajamento. Educação \& Sociedade (Impresso), v. 29, p. 63-79, 2009.

KOBAYASHI, M.C.M.;SOMMERHALDER, A.; ALVES, F. D..O que temos para brincar? Um estudo sobre os brinquedos encontrados na educação infantil. Revista NUPEM (Impresso), v. 7, p. 147-162, 2015.

LIMA, V.C., LIMA, M.R. de, MELO, V. F., MOTTA, A.C.V., DIONÍSIO, J.A., FAVARETTO, N., SIRTOLI, A.E., CARVALHO, A.R., BICCA NETO, H., RODRIGUES, R. Promoção do ensino de solos através de cursos, eventos e publicações de extensão para professores do nível fundamental e médio. Expressa Extensão, Pelotas, v. 8, n. 1-2, jul/dez 2003. CD-Rom.

LOUREIRO, C. F. B.; LIMA, M. J. G. S.. Educação Ambiental e educação científica na perspectiva ciência, tecnologia e sociedade (CTS): pilares para uma educação crítica. Acta Scientiae (ULBRA), v. 11, p. 88-100, 2009.

LEAL, M.C. R. Refletindo sobre a prática da Educação Ambiental na Escola: Da Teoria à Ação. Encontros (Rio de Janeiro), v. 17, p. 28-39, 2011.

LUZZI, D. A. . Educação e Meio Ambiente, uma relação intrinseca. 1. ed. São Paulo: Manole, 2012. v. 1500. 200p.

MALDONADO, D.P.A.; WILLIAMS, L.C.A. . O Comportamento agressivo de crianças do sexo masculino na escola e sua relação com violência doméstica.. Psicologia em Estudo, v. 10, p. 353-362, 2005.

MEDEIROS, L. C. S.; LEDERMAN, H. M. ; MORAIS, M. B. Lactose Malabsorption, Calcium Intake, and Bone Mass in Children and Adolescents. Journal of Pediatric Gastroenterology and Nutrition, v. 54, p. 204-209, 2012.

MERGULHÃO, M. C.; TRIVELATO, S.L.F.. A Diversão e o Aprendizado de Mãos Dadas. Revista Eletrônica: Mestrado em Educação Ambiental, vol. 15, julho/dezembro, 2005.

MARIN, A. A.; OLIVEIRA, H. T. ; COMAR, M. V. . A Educação Ambiental num contexto da complexidade do campo teórico da percepção. Interciencia (Caracas), Venezuela, v. 28, n.10, p. 616-619, 2003.

MOREIRA, D. A. Inovações, Habilidades e Competências: O Papel da Alfabetização Funcional. In: MOREIRA, D. A.; QUEIROZ, A.C.S. (Org.). Inovação Organizacional e Tecnológica. 01ed. São Paulo: Thomson Learning, 2006, v. 01, p. 157-179.

NEVES, M. A Educação em Valores Através da Prática de Gincanas. 2003. Monografia. (Aperfeiçoamento/Especialização em Gestão Escolar) Universidade do Estado da Bahia. Orientador: Solange de Oliveira Guimarães.

OLIVEIRA, J. E. B. M. A preceptoria na Escola. 1. ed. São Paulo: Editora Quadrante, Sociedade Publicações Culturais, 2017. v. 1. 164p. 
OLIVEIRA, H. T.; FARIAS, C. R. O. ; PAVESI, A. . Educação Ambiental no ensino superior brasileiro: caminhos percorridos e perspectivas para políticas públicas. Revista Brasileira de Educação Ambiental (Online), v. II, p. 91-101, 2008.

PAVESI, A.; FREITAS, D.; LOPES, B. P. C. S. Horticultura comunitária e construção de sistemas socioecológicos sustentáveis. Amazônia - Revista de Educação em Ciências e Matemáticas (Online), v. 10, p. 19-29, 2013.

PAXE, I. Gestão democrática da escola pública: Propostas à reforma educacional em Angola. Revista Educação e Fronteiras on-line, v.4, p. 39-49, 2014.

PEDRO, N.; PEIXOTO, F. Satisfação profissional e auto-estima em professores dos 2.ํ e 3.ำ ciclos do Ensino Básico. Aná. Psicológica [online]. 2006, vol.24, n.2 [citado 2013-08-19], pp. 247-262.

PELICIONI, A. F. Educação Ambiental com estudantes percepções e práticas ambientais. In: VALDEMIR, A. R. A Educação Ambiental na trilha. Botucatu: Tipomic, 2000. p.106.

PIAGET, J. Seis Estudos de Psicologia. Rio de Janeiro: Editora Forense, 1980. PIAGET, J.; INHELDER, B. A psicologia da criança. Rio de Janeiro: Ed.Bertrand Brasil, 1994.

QUEIROZ E.; MELO, M. F. A. A perspectiva sociocultural e as interações lúdicas nos primeiros anos da infância: revendo contribuições. Revista Brasileira de Crescimento e Desenvolvimento Humano, São Paulo-SP, v. 14, n. 02, p. 4653, 2004.

QUEIROZ, M. T. A.; SABARA, M. G.; QUEIROZ, C. A.; LIMA, L.R. P.; LEAO, M. M. D.; AMORIM, C. C.. Estudo de Caso: Análise Espaço-Temporal do Ribeirão Caladinho, Bacia Hidrográfica do Rio Piracicaba, Minas Gerais, para Abastecimento Público. Ciência e Natura, v. 37, p. 141-150, 2015.

QUEIROZ, M. T. A.; SABARA, M. G.; QUEIROZ, C. A.; LEAO, M. M. D.; AMORIM, C. C.. Oficinas Educativas: Qualidade da Água e Proteção Ambiental. Revista Brasileira de Educação Ambiental (Online), v. 10, p. 176186-186, 2015.

RAMOS, M.N. Concepções e práticas pedagógicas nas Escolas Técnicas do Sistema Único de Saúde: fundamentos e contradições. Revista Trabalho, Educação e Saúde. Rio de Janeiro, v. 7, suplemento, p. 153-173, 2009.

RAMOS, M.N. Trabalho, educação e correntes pedagógicas no Brasil: um estudo a partir da formação dos trabalhadores técnicos de saúde. Rio de Janeiro, UFRJ, 2010.

REPETTO, M. ; LIMA, J. I.; CARVALHO, F. ; KOWALCZUK, V. G. L.; MOREIRA, J. L. G.; LIMA, L. C. (Orgs.) . Produção de Material didático para a Diversidade. 01. ed. Boa Vista: Editora da UFRR, 2013. v. 1000. 169p . 
RÖHR, F. The Subject-Object-Relationship in Karl Jaspers' Periechontology - A Contribution to an Education for Openness, Tolerance and Existential Realization. ETD: Educação Temática Digital, v. 18, p. 596, 2016.

ROJO, S. Teatro político actual: la dramarturgia de Guillermo Calderón. Meridional Revista chilena de estudios latino americanos, v.5, p. 109-129, 2015.

SANTOS, A. N. F. Educação Ambiental: Desafios à Formação Docente. Educadores Em Ação, Uberlândia - MG, v. 1, p. 22-26, 2002.

SILVA, F. S.; CUNHA, M. C. Processos formativos na produção oral: análise de uma experiência em um curso de Português Língua Estrangeira. Signotica (UFG), v. 30, p. 00-00, 2018.

TAMAIO, I. $A$ Mediação do professor na construção do conceito de natureza. Campinas, 2000. Dissert.(Mestr.) FE/Unicamp.

VALLE, A. H.; BOGA, D J. Racionalidad e Irracionalidad de la Acción Pública. Sobre las posibilidades de construcción racional de la política. Revista Eleuthera, v. 4, p. 25-46, 2012.

VIANNA, T.; STRAZZACAPPA, M. Teatro na educação: Reinventando mundos. In: FERREIRA, S. (Org.) O Ensino das Artes: Construindo caminhos. Campinas, Papirus, 2001.

VILLELA, J.N.; EIGENHEER, E. M. Mudança comportamental do consumidor a partir de sacolas plásticas: iniciativa em prol da sustentabilidade em comunidade cristã. Relatórios de Pesquisa em Engenharia de Produção (UFF), v. 11, p. 120, 2011. 